\title{
SEMBLANZA HISTÓRICA DEL UNICAMERALISMO Y BICAMERALISMO EN COLOMBIA*
}

\section{Aroldo Guardiola Ibarra**}

Fecha de recibido: 2 de agosto de 2013.

Fecha de aprobado: 14 de febrero de 2014.

Artículo de Reflexión

Forma de citación: Guardiola, A. (2014). Semblanza histórica del unicameralismo y bicameralismo en Colombia. Revista Prolegómenos. Derechos y Valores, 17, 33, 97-108.

\section{Resumen}

En este artículo se presenta una semblanza histórica del unicameralismo y bicameralismo en Colombia, ; en cada periodo abordado se realiza una somera descripción del contexto sociopolítico que enmarcó la expedición de las ocho constituciones políticas que, a lo largo de su existencia como nación independiente, se ha dado en nuestro país y que se examinan específicamente en el tema del poder legislativo. Se toma como punto de partida la conceptualización acerca del derecho parlamentario, para involucrar los elementos políticos y valorativos inherentes a la institución parlamentaria.

\section{Palabras claves:}

Unicameralismo, bicameralismo, derecho parlamentario, régimen político.

\section{HISTORIC SKETCH OF UNICAMERALISM AND BICAMERALISM IN COLOMBIA}

\begin{abstract}
The article presents an historic sketch of unicameralism and bicameralism in Colombia; in each period addressed, a brief description of the socio-political context that framed the issue of eight political constitutions through the existence of Colombia as an independent nation is made, examining said constitutions regarding specifically the subject of

* Este artículo es un producto del proyecto de investigación titulado. «Percepción de la viabilidad y condiciones políticas para adoptar el sistema unicameral en Colombia», adscrito al centro de investigación de la Universidad Cooperativa de Colombia, Seccional Santa Marta.

** Licenciado en Lenguas Modernas. Especialista en Planeación Territorial. Magister en estudios político.económicos. Docente-investigador del programa de Derecho de la Universidad Cooperativa de Colombia, Seccional Santa Marta. Doctorante en Pensamiento Complejo de la Multiversidad Mundo Real. Edgar Morin. Correo electrónico: nodocaribe@yahoo.com
\end{abstract}


legislative power. A conceptualization about parliamentary law serves as starting point to involve the inherent political and evaluative elements to the parliamentary institution.

\title{
Keywords:
}

Unicameralism, bicameralism, parliamentary law, political regime.

\section{ESBOÇO HISTÓRICO DE UNICAMERALISMO E BICAMERALISMO NA COLÔMBIA}

\begin{abstract}
Resumo
O artigo apresenta um esboço histórico de unicameralismo e bicameralismo na Colômbia; em cada período abordado, uma breve descrição do contexto sócio-político que colocou a questão de oito constituições políticas através da existência de Colômbia como uma nação independente é feita, examinando disse constituições referentes especificamente o tema do poder legislativo. A conceituação sobre a lei parlamentar serve como ponto de partida para envolver os elementos políticos e avaliativas inerentes à instituição parlamentar.
\end{abstract}

\section{Palavras-Chave:}

Unicameralismo, Bicameralismo, Lei parlamentar, Regime político

\section{INTRODUCCIÓN}

En este artículo se presenta una semblanza histórica del unicameralismo y bicameralismo en Colombia. Se realiza una somera descripción del contexto sociopolítico que enmarcó la expedición de las ocho constituciones políticas que, a lo largo de su existencia como nación independiente, se dio en nuestro país desde 1821 hasta la fecha.

Actualmente, existe en Colombia por definición constitucional un Estado Social de Derecho, políticamente centralizado, con un Poder Legislativo bicameral, dentro de la estructura de un Estado Unitario. El bicameralismo es uno de los problemas que se le endilgan a la organización del poder político y el tema que más controversia suscita a la hora de evaluar el rol de la rama legislativa

La crítica señala la inconveniencia del sistema bicameral de nuestro Congreso, porque retrasa el trámite y elaboración de las leyes, genera poca efectividad, incrementa la burocracia y el despilfarro del tesoro público, así como la lenta adopción de trascendentales decisiones.

El bicameralismo en Colombia, de acuerdo con los analistas, es un rezago de sistemas representativos que si bien funcionan en otros continentes, para nuestra situación actual es arcaico, usufrutuado por una casta política caciquista, que por mantener sus prebendas y su caudillismo se opone de manera acérrima a los cambios institucionales, políticos y sociales.

Ni siquiera en la Asamblea Constituyente de 1991 los proyectos reformatorios que se presentaron, tendientes a establecer el unicameralismo en Colombia fueron de buen recibo, pese a la seriedad de los argumentos de quienes consideraron que con el establecimiento de un Congreso unicameral se daría un golpe certero a la rapacidad burocrática y se maximizaría el aprovechamiento del recurso legislativo, se 
evitaría la duplicidad de trabajo y de tiempo para resolver todo lo relacionado con la tarea del órgano legislativo de control político y de producción de las leyes.

Pero el análisis de la estructura, la función y la crisis del Congreso guardan relación con la situación actual del debate público acerca del rol del régimen presidencial existente en Colombia y la necesidad de profundizar en la democracia participativa, con el fin de alcanzar en nuestro país lo que Amartya Sen denomina en La Idea de la Justicia el gobierno de la discusión, para resaltar «el papel crucial del razonamiento público en la práctica de la democracia» (Sen, 2009, p. 356).

\section{EL DERECHO PARLAMENTARIO Y LOS REGÍMENES POLÍTICOS}

El abordaje de la relación de estas dos categorías exige delimitar su conceptualización. El derecho parlamentario, de acuerdo con Francisco Berlín Valenzuela, involucra los elementos políticos y valorativos inherentes a la institución parlamentaria, a los cuales le agrega las normas que rigen su actividad, su organización y funcionamiento. Para este autor, no se puede prescindir de los elementos sociológicos ni los ideales y creencias que dan sentido a las instituciones políticas, consagrados en las constituciones de cada Estado porque, en últimas, son la expresión normativa de los factores reales de poder de una sociedad. (2006, p. 30).

El derecho parlamentario «es el conjunto de normas que crean, establecen, impulsan, garantizan y rigen las acciones de los parlamentos, las interrelaciones sociopolíticas que mantienen con los otros poderes del Estado, los partidos políticos, las instancias de la sociedad civil y los individuos, así como los valores y principios que animan su existencia institucional y lo motivan a procurar su realización, por haber sido instituidos por el pueblo como expresión de su querer ser político» (Berlín, 2006, p. 34).
Es bien importante entonces, por su naturaleza, por su rol y por sus funciones, la relación que guarda la institución parlamentaria con el régimen político de una nación, esto es, la forma en que revisten las estructuras del Estado, su organización e institucionalización; el papel de la fuerzas políticas (partidos o grupos de presión), y sus relaciones en la conformación del poder político. El régimen político, en consecuencia, responde al análisis concreto de la realidad política. ${ }^{1}$

Se establece en este marco referencial la diferencia entre régimen presidencial y régimen parlamentario puesto que son los regímenes predominantes hoy en el mundo contemporáneo, aunque es el primero el que ha prevalecido en nuestra historia política nacional. El régimen presidencial se caracteriza por la excesiva centralización del poder político en la rama ejecutiva, cuya jefatura recae en la persona del presidente, el cual goza de una gran influencia en la elaboración de las leyes y en la toma de decisiones del congreso.

Se le atribuyen al régimen presidencial sobresalientes características, aunque con matizaciones y diferencia en distintos países ${ }^{2}$, como las siguientes el presidente del poder ejecutivo es elegido por el pueblo y concentra al tiempo la jefatura del Estado y del gobierno. Si bien el presidente no puede disolver el congreso, este no puede sancionarlo con un voto de censura. El presidente puede ser miembro de un partido diferente al mayoritario en el Congreso y dispone libremente de la conformación de su gabinete.

1 Maurice Duverger establece una nítida diferencia entre régimen y sistema político. Considera el sistema político como la confluencia del sistema social (económicos, técnicos, culturales, ideológicos, históricos, etc.) estudiado bajo las perspectivas de sus aspectos políticos. Y caracteriza al régimen político como el subsistema constituido por el conjunto de las instituciones política s de un sistema social. (1992, p. 33).

2 Ver al respecto las tesis del Jurista mexicano Jorge Carpizo, citado por Berlín Valenzuela en la obra referenciada en este trabajo. 
A diferencia de los regímenes presidenciales, al régimen parlamentario se le atribuye una relación con el poder ejecutivo de coordinación y compenetración entre ambos poderes. No existe el riego de la subordinación del legislativo por el poder ejecutivo. La existencia de un parlamento verdaderamente independiente limita el uso arbitrario del poder y propicia mayor competencia entre los partidos políticos. Pero la principal característica de este régimen es que la designación del ejecutivo deriva del órgano legislativo.

Otra característica sobresaliente de los regímenes parlamentarios consiste en que este puede exigir responsabilidad política al gobierno en pleno o a uno de sus miembros. Además, un voto de censura o desconfianza por parte del congreso obliga a la dimisión del gobierno, aunque este puede responder con la disolución del poder legislativo y en ese caso será el pueblo el que en elecciones generales decida quien tiene la razón.

Para aterrizar esta relación de encuentros y desencuentros entre el régimen político y el Congreso de la República, presentamos en el siguiente apartado una mirada retrospectiva de nuestra historia política para avanzar en la concreción de los propósitos de este artículo.

\section{SEMBLANZA HISTÓRICA}

En el proceso de la primera independencia de la Nueva Granada, signada por serias divergencias entre centralistas y federalistas, las provincias de Cundinamarca, de Tunja, de Antioquia y de Cartagena de indias se constituyeron en Estados y expidieron sus propias constituciones políticas.

Un Colegio Constituyente de la Provincia de Cundinamarca expidió en marzo de 1811 una constitución en la cual se estableció una monarquía Constitucional y un poder legislativo, constituido por una sola cámara, integrada por diecinueve miembros nombrados por un colegio electoral. Un año después, una representación de esta provincia revisó el texto constitucional, estableció la República de Cundinamarca con un gobierno popular representativo. Modificó el poder legislativo, el cual se estructuró con dos cámaras, Senado y Cámara de Representantes, cuyos miembros serían elegidos por el Colegio electoral para un período de dos años.

Las Constituciones Políticas de las otras provincias arriba mencionadas, declararon, sin ambigüedad, su independencia de España durantelosaños de 1811y 1812, se establecieron como república con poder ejecutivo, judicial y legislativo, y estructuraron esta última rama del poder político con su respectivo congreso bicameral. Aunque tres años después delegados de la provincia de Antioquia, reunidos en Convención, expidieron una segunda Constitución de carácter provisional, en la cual se establece un poder legislativo conformado por una sola cámara.Mucho más tarde, como resultado de la segunda y definitiva revolución de independencia, el Congreso llevado a cabo en Villa del Rosario de Cúcuta expidió, en agosto de 1821, la Constitución Política de la primera República de Colombia. La coyuntura que enmarcó este evento fue resumida por el propio Bolívar, para quien «la no existencia de una dirección general de rentas, la incoherencia de todos los ramos, mi ausencia de la capital, y mi estada en el ejército, todo esto y muchas cosas tienen por así decirlo la república en orfandad»(Gilmore, 1995, p. 32). Y agregaba, además, que Colombia «en lugar de ser un cuerpo social, es un cuerpo militar» (Gilmore, 1995, p. 32). Tales afirmaciones sintetizan, en buena medida, la situación política y social que enmarcó el Congreso Constituyente de Cúcuta.

Las deliberaciones de este Congreso, presidido por Antonio Nariño, estuvieron signadas por un arduo debate entre centralistas y federalistas partidarios, los primeros, de un Estado Unitario y, los segundos, defensores del Estado descentralizado y federalizado. No obstante, la organización estatal que se delinea en la Constitución sancionada por El Libertador incorpora la concepción liberal de la división tripartita del poder político y la creación de 
un gobierno representativo, republicano $y$ centralizado, expresión de un Estado Unitario. Se consagra, en consecuencia, un poder legislativo integrado por dos cámaras «con iguales facultades en materia legislativa, pero con atribuciones peculiares en otras materias» (Pérez, 1997,p. 171).

Siete años después, la República de Colombia no se había consolidado como una nación, porque se hallaba muy lejos de alcanzar la estabilidad política y la cohesión de los distintos intereses regionales en conflicto. Muy a pesar de la objeción de El Libertador Simón Bolívar, se esgrimía desde distintas provincias la federación como una opción alternativa a los apremiantes problemas del separatismo que amenazaba la unidad de la joven nación.

«El clima bélico se trasladó de los campos de batalla, al congreso, a las convenciones, a las diatribas de los órganos periodísticos, a las intrigas del clero, a las rivalidades entre civilistas y militaristas, a las conspiraciones y a la revuelta y rebeldía popular. Los intereses mezquinos y sectoriales dominaron la dinámica política. En consecuencia, la unidad de la República de Colombia, integrada por la Nueva Granada, Venezuela y Quito se deterioró, asediada por el galope de los caudillos separatistas y en medio de una confrontación política sórdida y sin cuartel» (Guardiola, 2010, p. 197).

El 2 de marzo de 1828, el Congreso convocó a la Convención de Ocaña, pero la pugnacidad entre bolivarianos y santanderistas, entre federalistas y centralistas precipitaron el fracaso de la Convención. Bolívar, asumiendo poderes dictatoriales, decidió gobernar por decreto, hasta que una nueva Convención convocada para el 2 de enero de 1830 estableciera una nueva constitución.

Pero muerto El Libertador y disuelta la República de Colombia, otros fueron los acontecimientos políticos: 19 provincias neogranadinas reunidas en una Convención o Asamblea Constitucional en octubre de 1831, que sesionó hasta el primero de abril de 1832, instituyeron el Estado de la Nueva Granada, Estado centralizado que estatuye la división de poderes y una rama legislativa con dos cámaras, suprime los departamentos y establece las asambleas provinciales directamente subordinadas al Congreso y al Poder presidencial.

\section{Para Robert Gilmore en esta constitución}

"(...) el congreso era el poder dominante entre las tres ramas del gobierno. Existía la separación, aunque no un equilibrio, entre los poderes. La rama ejecutiva estaba limitada en sus facultades tanto por la intervención del congreso como por el consejo de Estado, que sería elegido por el congreso y otorgado amplios poderes durante los recesos del congreso» (1995, p. 108).

Esta constitución experimentó una calma chicha dentro de los siguientes siete años, pero una guerra civil de carácter nacional no solo la desdibujó sino que cuestionó la legitimidad del poder político concentrado en la ciudad de Bogotá. Ese conflicto bélico es conocido en la Historia nacional como La Guerra de los Supremos, caracterizada, por muchos historiadores, como la primera guerra civil en el territorio nacional y, de acuerdo con la proclama de los caudillos de las provincias, como Francisco José Carmona en las Llanuras del Caribe, José María Obando en el Suroccidental, Salvador Córdoba en Antioquia, Manuel González en Santander y Tomás Herrera en el Istmo de Panamá, su principal cometido era la instauración del sistema federal en todo el país, respondiendo así al interés de muchas provincias de reformar la Constitución Política.

La consecuencia de la derrota de los Supremos fue la promulgación en 1843 de una nueva constitución política que recentraliza el poder del Estado; reitera la estructuración de un congreso bicameral, constituido por el Senado y la Cámara de Representantes, reduce a cero la autonomía de las asambleas provinciales y 
robustece el poder presidencial, otorgándole facultad de iniciativa legislativa e incrementando su poder de veto (Gilmore, 1995, p. 136).

No obstante, la Nueva Granada no alcanza la estabilidad política. Una nueva administración al frente de la República, en cabeza de Tomás Cipriano de Mosquera y su Ministro de Hacienda Florentino González, emprende un proceso de reformas económicas tendientes a favorecer el libre comercio, pero exacerban los sentimientos oposicionistas de los trabajadores textileros y los artesanos de las confecciones que origina la creación de las Sociedades Democráticas. En la base de las disputas se hallan las demandas de libertad y democracia política que se reiteran en los venideros debates electorales por la presidencia.

El 7 de marzo de 1849, ante la indefinición arrojada por los resultados electorales de las elecciones de 1848, fue elegido en el congreso José Hilario López como Presidente de la Nueva Granada, quien proclamó la República Democrática como el ideal de su administración, en momentos en que bullía el malestar social, acicateado por la exigencia de libertad de los esclavos y la oposición de los esclavistas que se levantaron en el suroccidente del país; y la reivindicación de las Sociedades Democráticas de la separación de la iglesia del Estado y la necesidad de impartir una educación laica.

Otros temas de debate lo constituyeron la liberación económica y la integración al mercado internacional; la reforma a la Constitución Política promulgada en 1843 y considerada por sus críticos como cuasi monárquica; la abolición de los resguardos indígenas y el monopolio del tabaco; la modernización y secularización de la sociedad; y, como un reconocimiento de los derechos de las provincias, la descentralización política y la elección popular de gobernadores. El congreso de la República, considerando que la constitución de 1843 no satisfacía cumplidamente los deseos y necesidades de la nación, expidió un nuevo ordenamiento constitucional el 20 de mayo de 1853. Esta normatividad divide al territorio de la Nueva Granada en provincias con capacidad para disponer lo que juzgue conveniente a su organización, régimen y administración interior, sin afectar las competencias del gobierno general. Estableció un poder legislativo compuesto por un congreso de dos cámaras, en una de las cuales, la cámara de representantes, las provincias deberían estar representadas aunque no alcanzara su población el número establecido por el artículo reglamentario.

La nueva constitución garantiza los derechos individuales, la libertad de prensa, la separación de la iglesia del Estado, se incrementó la descentralización, la autonomía de las provincias, cuyo gobierno recaía en la responsabilidad de un gobernador y una legislatura provincial de elección popular.

Estas reformas del medio siglo sentaron las bases jurídico-políticas para que a finales de la década del cincuenta se estableciera un nuevo sistema político, estatuido mediante la promulgación de la Constitución de 1858 que dio origen a la denominada Confederación Granadina que, según el parecer del constitucionalista Jacobo Pérez escobar, denomina de manera inapropiada el federalismo establecido.

En el artículo 1 del capítulo I de esta constitución se señala: Los estados de Antioquia, Bolívar, Boyacá, Cauca, Cundinamarca, Magdalena, Panamá y Santander se confederan a perpetuidad, forman una nación soberana, libre e independiente bajo la denominación de "Confederación Granadina» y se someten a las decisiones del gobierno general, en los términos que se establecen en esta constitución.

Aunque la reforma constitucional establece un nuevo sistema político, se consagra, al igual que en las anteriores, un poder legislativo integrado por dos cámaras. La primera de estas, el senado, integrado por tres senadores de cada Estado, y la segunda, la cámara de representantes, conformada a razón de un representante por cada sesenta mil habitantes y uno más por un 
residuo superior a veinticinco mil. Por tal razón, a diferencia de lo que afirman otros analistas, el calado de la reforma no alcanza la dimensión de una revolución social y política, si tenemos en cuenta además que continúan pendientes asuntos como la secularización del Estado, la abolición de la esclavitud, que persiste en muchas haciendas, a pesar de la ley que la prohíbe, y la propiedad agraria presenta altos niveles de concentración.

La estabilidad política ganada con las reformas del medio siglo se malogró con el levantamiento del general Tomás Cipriano de Mosquera, gobernador del Estado soberano del Cauca, que en febrero de 1860 anunció su separación de la Confederación Granadina, «como protesta porque el congreso había invadido con sus leyes la soberanía de los Estados. Se unió entonces con sus antiguos enemigos los generales Obando y López, porque la federación así lo exigía» (Pérez, 1997, p. 183). Mosquera, después de derrotar con su ejército a las fuerzas oficiales y de firmar con los siete Estados soberanos el Pacto de la Unión, se proclamó Presidente provisorio de los Estados Unidos de la Nueva Granada y supremo director de la guerra. No obstante, las circunstancias políticas lo obligaron a convocar una convención nacional que se instaló en febrero de 1863 en Rionegro.

Una nueva constitución fue sancionada por la Convención de Rionegro. En ella, además de estatuir la división de poderes y un congreso bicameral, se otorga autonomía y soberanía a los Estados que se «unen y confederan a perpetuidad consultando su seguridad exterior y reciproco auxilio y forman una nación libre, soberana e independiente, bajo el nombre de Estados Unidos de Colombia» (Constitución política de 1863. Artículo 1).

En este texto se profundizan las reformas democráticas, tales como la abolición de la pena de muerte; la supresión de la esclavitud; el reconocimiento de los derechos individuales de los ciudadanos; la libertad absoluta de imprenta y de circulación de los impresos; la libertad de pensamiento sin limitación alguna; el pluralismo religioso y la separación de la iglesia del Estado; la inviolabilidad del domicilio y los escritos privados; la libertad de asociación, etc.

La Constitución de Rionegro le atribuye al gobierno de la Unión la responsabilidad de las relaciones exteriores; la defensa exterior y el derecho de declarar y dirigir la guerra y hacer la paz. Por tanto, las relaciones internacionales recaen en el gobierno de la Unión o gobierno general; se estatuyó la no existencia del monopolio de la fuerza por parte del Estado central; por el contrario, los Estados soberanos organizaron sus propias milicias al tenor de sus leyes particulares y, en consecuencia, el manejo del orden público fue descentralizado, resultado de procesos de concertación entre el gobierno de la Unión y los Estados Confederados.

Si bien, con esta Constitución se sustrajo al país del limbo constitucional en que se encontraba, debido a que hasta su promulgación los Estados soberanos solo los unía el Pacto de la Unión, los constituyentes de Rionegro no propiciaron el fortalecimiento de la dirección general o central del Estado, por el contrario, con la promulgación de esta norma fundamental hicieron posible la combinación del sistema federalista con postulados constitucionales propios de una confederación de Estados independientes ${ }^{3}$. Pero con ello no solo se descentralizó el poder político sino también las rebeliones, los levantamientos y los conflictos armados.

En consecuencia, las instituciones políticas consagradas en la Constitución de 1863 no garantizaron la estabilidad política y económica

3 Los Estados Unidos de Colombia son soberanos y autónomos, constituidos bajo el doble vínculo del pacto y la constitución. Disponen de sus propias fuerzas armadas o milicias y de un manejo particular del orden público y de los conflictos internos como si fuesen verdaderos Estados independientes. Le imponen serias cortapisas al nivel central en el manejo de la hacienda pública y sólo reservan al gobierno general las relaciones exteriores y el manejo de la guerra y la paz con los otros estados independientes. (Constitución Política de Rionegro). 
del país. Un nuevo proyecto político, el de $L a$ Regeneración, liderado por Rafael Núñez, se abrió camino respondiendo a las exigencias de los sectores exportadores que reclamaban la organización de un Estado fuerte y centralizado, con capacidad de intervenir en la economía y en la construcción de modernos medios de comunicación, como el sistema ferroviario. En 1880, Núñez fue elegido Presidente de la República, y cuatro años después reelegido como primer mandatario de la Nación. El 10 de septiembre de 1885, después de salir victorioso de la guerra civil de ese año, convocó por decreto un Consejo Nacional de Delegatarios, compuesto por dos delegados de cada uno de los nueve Estados soberanos, con el propósito de redactar una nueva constitución política.

El nuevo texto constitucional, aprobado el 4 de agosto de 1886, estableció el sistema unitario como forma de Estado y de consolidación de la soberanía; la nación adquiere nuevamente el nombre de República de Colombia, dividida administrativamente en departamentos, en provincias y distritos municipales, los gobernadores se nombran como agentes del Presidente de la República, se crea un ejército permanente y se establece la pena de muerte.

La Constitución de 1886 establece, además, la elección del Presidente de la República por las asambleas electorales por un período de seis años; un ejecutivo fuerte sin responsabilidad presidencial ante sus electores y denominados por sus propios ideólogos como «monarquía electiva»; facultad conferida al presidente para declarar el Estado de Sitio en toda la nación o en parte de ella; un Senado para una duración de seis años y compuesto por tres miembros de cada departamento, elegidos por las asambleas departamentales; y una Cámara de Representantes elegida para un período de cuatro años por los ciudadanos que supieran leer y escribir, o tuvieran una renta anual de quinientos pesos, o una propiedad inmueble de mil quinientos pesos.

En síntesis, los pilares sobre los que se construyeron los imaginarios de nuestra nación no presentan una raigambre en la historia del conjunto de los actores sociales. De ello dan fe en este período el escudo, el himno y la bandera, cuyas imágenes simbolizan elementos de la cultura hispánica, griega y francesa, cuando debieran fundamentarse en nuestra historia y cultura nacionales.

\section{LA CONSTITUYENTE DE 1991}

Diversas reformas experimentó la Constitución de 1886 a lo largo del siglo XX. Se destacan, por su importancia, las reformas de 1910; la de 1936; la de 1945; la de 1968 y 1986, destinadas a responder a las circunstancias políticas y económicas que surgieron durante esta centuria. Pero tales eventos reformatorios solo paliaron la profunda crisis de legitimidad de las instituciones estatales, como la del Congreso de la República, la de la administración de justicia, la del Ministerio público y la de los partidos políticos que avalaban con sus programas $y$ acciones las decisiones gubernamentales.

En la década del ochenta, ante la agudización de la crisis social y política y los problemas de orden público, los movimientos estudiantiles, cívicos, étnicos y agrarios demandaron en todo el país radicales reformas para relegitimar la organización estatal sobre la base de un nuevo consenso ciudadano.

Ante los fallidos intentos de reforma de la constitución en el Congreso de la República, el 23 de agosto de 1990 el Presidente Cesar Gaviria Trujillo y los representantes de los partidos y movimientos políticos celebraron un acuerdo para la convocatoria de una Asamblea Constitucional, el 9 de diciembre de ese mismo año, para que sesionara entre el 5 de febrero y el 4 de julio de 1991. El proceso eleccionario dejó como resultado la elección de 70 delegados de los partidos políticos, de los movimientos sociales y regionales. La Asamblea Constituyente se instaló en la fecha convenida, ante la expectativa de los colombianos que guardaban la esperanza de que dicha asamblea sentara las bases para la paz y la democracia en Colombia. 
En particular, en lo que se refiere al poder legislativo el debate en el seno de la comisión de la Constituyente encargada del asunto fue intenso y promisorio. He aquí una síntesis de ese debate:

\section{Las tesis de los defensores del Bicameralismo}

Los defensores del bicameralismo presentaron como justificación ideológica del Congreso bicameral la tesis de la cámara reflexiva. Argumentaron que el Senado es una instancia de reflexión, un factor de ponderación y un freno a los excesos de la Cámara Baja, impetuosa e irreflexiva por causa de su carácter popular. Es necesario subdividir el parlamento para que las dos cámaras se controlen políticamente entre sí, con el fin de evitar excesos en cada una de ellas. ${ }^{4}$

El equilibrio vendría no ya del encuentro de la juventud con la madurez, de lo impulsivo con el buen juicio sino de la sana confrontación de fuerzas políticas en movimiento encarnadas, respectivamente, en cada cámara. La labor legislativa, por su delicada índole, debe ser pausada, metódica y reflexiva porque el bicameralismo implica un instante de reflexión en la tramitación de las leyes.

Sostuvieron, además, que la estructura bicameral del poder legislativo es inseparable del régimen presidencial auténtico. La subdivisión del Congreso en dos asambleas distintas impide que el poder ejecutivo asuma un papel preponderante y facilita la solución a los contrastes eventuales del régimen presidencial. La opción bicameral se justifica con base en el principio de la repartición del poder, porque el fraccionamiento de los poderes de la representación popular en dos cámaras, evita el abuso derivado de la concentración del poder en una única Asamblea. ${ }^{5}$

4 Ver EL Abedul. Gaceta Constitucional Número 79. Bogotá. D.C. Mayo 22 de 1991.

5 En la gaceta citada antes, se señala además que el monocameralismo es una solución exótica en los regímenes de extirpe presidencial.

\section{LAS CRÍTICAS DE LOS DEFENSORES DEL UNICAMERALISMO}

Los críticos de bicameralismo argumentaron, por su parte, que el Senado y la Cámara de Representantes, con iguales funciones e idéntico período, son la misma cosa; se trata, en la práctica, de una sola cámara artificialmente dividida en dos partes que no tienen una actividad de importancia que las distinga ni una representación que por su origen lo justifique, en la medida en que tanto senadores como representantes provienen de las mismas circunscripciones $\mathrm{y}$, aun, de las mismas listas electorales.

Como sucede con las demás construcciones ideológicas surgidas alrededor del congreso bicameral, el modelo de las dos cámaras que se controlan entre sí es, a primera vista, muy coherente, pero examinado con lente crítico, se revela conceptualmente defectuoso e históricamente inconsistente con la realidad.

El Congreso actual, argumentaron, se distingue especialmente por su desesperante lentitud $e$ ineficiencia, sin embargo, han existido proyectos, especialmente del Gobierno, que se aprueban en tiempo récord, sin pausa. La figura del mensaje de urgencia ha permitido al Ejecutivo tramitar proyectos de ley en cuestión de días o incluso de horas. El famoso «pupitrazo», reduce al campo de la retórica cualquier argumento sobre «expedición pausada y juiciosa de las leyes». Todas las razones bicameralitas se derrumban cuando en el país se legisla mediante facultades extraordinarias del Ejecutivo.

Es bien conocido que en el texto definitivo de la Constitución de julio de 1991 se estableció el Estado Social de Derecho, aunque preservó su carácter de Estado Unitario; insertó los principios de la democracia participativa $y$ caracterizó a la nación colombiana como multiétnica y pluricultural. De acuerdo con la norma constitucional, Colombia se erige sobre la base del respeto de la dignidad humana, el trabajo y la solidaridad de las personas que 
integran a la sociedad. El cuerpo de normas constitucionales incluyó también el principio liberal de la tridivisión del poder, con un órgano legislativo constituido por dos cámaras, Senado y Cámara de Representantes.

Pero esta asamblea Constituyente y la Nueva Constitución Política, en contravía de la esperanza de los colombianos, no sustrajo al Congreso de su crisis política y de su crisis de legitimidad.

\section{LA CRISIS ACTUAL DEL CONGRESO}

En la actualidad, el Congreso de la República atraviesa por una profunda crisis de legitimidad, la cual va más allá de la calidad o cantidad de proyectos de ley tramitados y aprobados. El cuestionamiento que a diario recibe de la opinión pública y el descreimiento que hoy tiene la ciudadanía ante su función legislativa está asociado a la participación directa de buena parte de sus integrantes en el denominado escándalo de la parapolítica.

Según datos publicados por la prensa nacional, son más de sesenta congresistas los investigados por parapolítica y más de treinta condenados por la misma razón. Los pactos secretos con organizaciones ilegales, la aceptación de financiación de sus campañas electorales por parte de los paramilitares, o la práctica de constreñimiento al elector, o de complicidad en masacres y secuestros, son las principales acusaciones que se han puesto sobre el tapete.

Como un corolario de esta descomposición ética y moral de los congresistas parapolíticos, se señala la crisis de representatividad que ha sobrevenido con la llegada de políticos locales ubicados en segundo o tercer renglón de las listas que, en su momento, fueron conformadas para el Senado o la Cámara de Representantes, en la medida en que los registros muestran una votación alcanzada por estos muy por debajo de la votación que se requiere para elegir un concejal en la ciudad de Bogotá.
Ante la gravedad de la crisis del poder legislativo, las propuestas de solución han oscilado entre las solicitudes de revocatoria, pasando por la reforma a la Constitución Política para conformar un nuevo Congreso y castigar a los partidos políticos que acepten a candidatos ilegales dentro de sus filas, al igual que las demandas de reformar estructuralmente al Estado para depurar el ejercicio político, hasta la aparición, en momentos de mayor efervescencia, de movimientos de ciudadanos que mediante la recolección de firmas se plantean, sin que a la postre lo hayan logrado, desbancar a los senadores y representantes para proceder a conformar un nuevo congreso unicameral.

Pero además del fenómeno de la parapolítica, la crisis de legitimidad del congreso se profundizó con la aprobación de la Reforma a la Justicia por parte del Congreso de la República el 14 de junio de 2012. Mediante el régimen de inhabilidades de dicha reforma, se blinda a los congresistas destituidos por violarlo, los cuales no serían castigados con pérdida de investidura sino únicamente con nulidad de la elección, por tanto, no estarían impedidos para ejercer cargos públicos en el futuro.

Además, cuando se presenten procesos de pérdida de investidura de un congresista, serán sometidos a una doble instancia, de modo que el senador o representante a la cámara sancionado con esta medida podrá recurrir a una segunda sentencia dictada por el Consejo de Estado.

Ante tamaño despropósito, el país presenció el surgimiento de un gran movimiento de ciudadanos, que no vaciló en levantar la iniciativa de un referendo revocatorio de la reforma aprobada por el Congreso. Las redes sociales y, en general, los medios de comunicación en esta oportunidad le hicieron eco a la protesta de la ciudadanía. Este episodio del Congreso se cerró el 22 de junio de 2012 cuando el Presidente de la República Juan Manuel Santos anunció la objeción del acto legislativo aprobado por el Congreso y convocó a los parlamentarios 
a sesiones extraordinarias a finales del mes siguiente para revocar una reforma que despertó la indignación popular.

Ahondar en el análisis sobre la estructura y funcionamiento del Poder Legislativo en la Colombia de hoy es pertinente y de invaluable importancia, habida cuenta de que la búsqueda de la justicia social y la democracia de participación por parte de la sociedad civil colombiana exigen no solo poner en el escenario del Congreso los álgidos y urgentes problemas sociopolíticos y económicos ligados a la actividad del Poder Legislativo y atentatorios de la seguridad humana sino que exige, además, someterlos al cotidiano debate ciudadano para hacer del Estado y de sus instituciones un objeto del permanente escrutinio público.

En la teoría política contemporánea, toma fuerza la idea del razonamiento público para profundizar en la justicia y la práctica de la democracia. Precisamente, Amartya Sen, al respecto, señala que en la filosofía política el entendimiento de la democracia se ha extendido hasta el punto de considerarla no solo como demanda de elecciones públicas sino que incorpora la visión de más amplia perspectiva del gobierno por discusión, subrayando la deliberación ciudadana y el debate de opiniones en torno a cuestiones políticas públicas. ${ }^{6}$ Para Amartya Sen « (...) las cuestiones centrales en una comprensión amplia de la democracia son la participación política, el diálogo y la interacción pública» (2009, p. 356).

6 Giovanni Sartori, en su renombrado libro ¿Qué es la Democracia?, argumenta que la opinión pública auténtica y autónoma presupone libertad de pensamiento, libertad de expresión y policentrismo. Reivindica, por tanto, un individuo que pueda abrevar en todas las fuentes del pensamiento y libre para controlar la información que recibe. Sostiene también que para el ejercicio de la libertad de expresión no solo se necesita la tutela del sistema jurídico sino que el sujeto se encuentre libre de intimidaciones, para poder propagar lo que quiere decir. Añade además, que los medios de comunicación deben presentar una estructurapolicénctrica, distanta de las estructuras monocéntricas propias de los totalitarismos y las dictaduras. (Sartori,1994. pp. 57-64).
Esa visión amplia de la democracia, de la que nos habla Amartya Sen, nos lleva a considerar el contexto social y político en el que se enmarca la problemática del Congreso de la República. Registramos, de manera sucinta, la precaria legitimidad del conjunto de las instituciones políticas y el escepticismo generalizado de la ciudadanía frente a su ineficiente desempeño. A ello hay que agregarle «las imperfecciones de las estructuras de representación, los vacíos de expresión política democrática y pacífica, la mediación desequilibrada de los medios, el temor y la muerte, han minado la célula básica de la organización social democrática» (Echeverri, 2008, p. 27).

\section{A MANERA DE CONCLUSIONES}

En este artículo, avance de investigación, se presentó una semblanza histórica del bicameralismo y unicameralismo en Colombia desde la perspectiva del derecho parlamentario, como expresión de las interacciones sociopolíticas de los poderes del Estado con las distintas manifestaciones de la sociedad civil.

En particular, se registra el debate suscitado en el seno de la Constituyente del 91, a propósito de la estructuración del sistema bicameralista o unicameralista que los constituyentes reunidos en asamblea debían definirle al poder legislativo y que como resultado optó mayoritariamente por el primero.

Se enmarca, de esa manera, la actual crisis de legitimidad del Congreso, relacionada con el fenómeno de la parapolítica, la crisis de representatividad, asociada al escaso respaldo popular con el que cuentan quienes accedieron a una curul en el Senado o en la Cámara de Representantes, ante la falta absoluta de un buen número de parlamentarios investigados $y / o$ enjuiciados por parapolítica, y que dio origen a diversos iniciativas de revocatoria, al tiempo que diversos movimientos y redes sociales plantean la necesidad de avanzar en la construcción de ciudadanía, como estrategia nodal para la superación de la democracia licenciosa dominante en nuestro país. 


\section{REFERENCIAS}

Berlín, F. (2006). Derecho Parlamentario. Política y Derecho. México: Fondo de Cultura Económica.

Bobbio, N. 1997). Estado, Gobierno y Sociedad. Por una teoría general de la Política. Breviarios. Colombia: Fondo de Cultura Económica.

Chillán, M. d. C. \& García, I. (1991). Derecho Constitucional - Sistema Político y Senado. Reflexiones en torno al bicameralismo. El Abedul. Gaceta Constitucional, 79.

Duverger, M. (1992). Instituciones Política y Derecho Constitucional. Barcelona: Ariel.

Echeverry, R. 2008). Ciudadanía y Reforma Política. En ESAP. IICA. CLMR Misión Política en Colombia. Claves para pensar la ciudadanía. Tomo I. (p.54-78). Bogotá.

El Abedul, Gaceta Constitucional. (1991). 79,

Garavito, F. 2008). Medios y poder \& medios y Opinión \& medios y usuarios sobre la tela de una araña. En ESAP. IICA. CLMR Misión Política en Colombia. Claves para pensar la ciudadanía. Tomo I. (p.97-110).

Garrido, M. (2008). Notas sobre las ideas Políticas en Colombia. En ESAP. IICA. CLMR Misión Política en Colombia. Claves para pensar la ciudadanía. Tomo II.

Gilmore, R. L. (1995). ElFederalismo en Colombia. 1810-1858. Tomo I y II. Sociedad Santanderista de Colombia. Universidad externado de Colombia. Producción Editorial Editores Ltda.

González, F. 1997). Aproximación a la Configuración política de Colombia. En: para leer la Política. Ensayo de Historia política de Colombia. Tomo I. Capitulo I. CINEP. Bogotá.

GUETIERREZ, Carlos B. (2008). La Práctica política en Colombia. En ESAP. IICA. CLMR Misión Política en Colombia. Claves para pensar la ciudadanía. Tomo II.

Guardiola, A. 2010). La regionalización del caribe Colombiano. Ideas políticas y Enfoques Económicos. Santa Marta: Fundaregión.

Leal, F. 1989). Estado y Política en Colombia. Bogotá: TM Editores.

Liévano, I. 2001). Bolívar. Bogotá: Intermedio Editores.

Pérez, J. (1997). Derecho Constitucional Colombiano. Bogotá: Editorial Temis.

Pizarro, E. 2008). Colombia. Renovación o Colapso del sistema de partidos. ESAP. IICA. CLMR Misión Política en Colombia. Claves para pensar la ciudadanía. Tomo II.

Sen, A. 2010). La Idea de la Justica. Traducción de Hernando Valencia Villa. Bogotá: Taurus. Pensamiento.

Sartori, G. (1994). ¿Qué es la Democracia? Capitulo V. Colombia: Altamir Ediciones.

Tirado, A. 1989). El Estado y la Política en el siglo XIX. Nueva Historia de Colombia 2. República. Siglo XIX. Bogotá: Planeta.

Vásquez, H. 2008). Pensando acerca del Estado y de las instituciones sociales $y$ políticas. En ESAP. IICA. CLMR Misión Política en Colombia. Claves para pensar la ciudadanía. Tomo II. 